\title{
Drug Abuse
}

National Cancer Institute

\section{Source}

National Cancer Institute. Drug Abuse. NCI Thesaurus. Code C16522.

The use of a drug for a reason other than which it was intended or in a manner or in quantities other than directed. 